\title{
DIFFICULT AND DEFECTIVE CHILDREN
}

\author{
BY \\ A. DINGWALL FORDYCE, M.D., F.R.C.P., \\ Physician, Royal Liverpool Children's Hospital; \\ Certifying Officer, Liverpool Education Authority.
}

A child whose management and training never present difficulties is not a normal child, and when we speak of a 'difficult' child, we mean by the term special difficulty either in degree or nature, or in both. The difficulty is frequently one of behaviour, such as, for example, disobedience, lying, fighting, temper, thieving, enuresis. All such are instances of difficulty of excessive degree, because the normal child is occasionally disobedient, lies, fights, has fits of temper, makes petty thefts, and wets himself or his bed. But the difficulty may be different in nature. It may be of a social nature and show itself at home or at school in bullying, wanton hurting, apparently causeless turbulence, and possibly wandering away; or of a physical symptomatology such as sleeplessness, twitchings, refusal of food, indigestion and anæmia.

\section{Difficult children.}

Causative factors. - Confronted with a difficult child we have to consider primarily the cause of the trouble, and naturally we turn first to examination of the child himself. As the underlying cause of difficulty in the cases of normal children is often temporary physical disability, we seek first a physical cause, and among such causes and often unobtrusive in character are throat infections, bacilluria, fatigue and indigestion.

Indigestion may be either the cause or the result of difficulty. When it is the cause, its successful treatment cures the difficulty: when it is the result, medicinal and dietetic treatment are naturally inefficacious, and further investigation and action are indicated.

Not only the physical condition, but the mental state also demands examination. Is the child mentally defective, or although mentally within the limits of the normal, does he possess innate temperamental qualities which render specially directed management advisable? Many mentally defective children are difficult children but there are many difficult children who are mentally normal, and the responsibility for the cause of the difficulty may not rest with the child at all but be environmental in nature, and rest mainly on the shoulders of his parents or guardian. Guardianship may be unwise or irresponsible; parental care may be foolish or faulty; there may be lack of supervision or excessive care or mal-administration. 
The doctor in the past has generally been regarded as a physical adviser and much of his work still is purely such, but he must also be to some extent a psychiatrist. He must, when necessary, probe into mental and temperamental conditions, personal, domestic and scholastic, and be prepared to give advice and act as conditions demand. Difficulties, ungrappled with, may lead to serious disorder-physical, mental and social.

When the fault lies solely with the child we may be able to do a great deal by restoring normal health, and when parents or guardian are willing and able to aid us, much can be done when the source of difficulty is mainly environmental. Unfortunately, however, only too often we are not allowed, or have not the opportunity, seriously to deal with the problems which exist. All of us with families know that it is supremely hard to be a good parent, even without reading the parents' questionnaire set by our American friends. The neurotic or psychopathic parent resents criticism, discredits explanation, and flits with her child from doctor to doctor. The two alternative courses which can be followed are either to place the facts of the position plainly before the parent and attempt to obtain the desired change in conditions by the force of reasoning, or so to deal with family affairs, including possibly a holiday for the mother, as to obtain the conditions necessary for improvement of the child.

Perhaps the most difficult cases are those in which disharmony exists between mother and father. If parents are divorced or separated, not only is the enormous value of biparental influence and care lost, but parental influence is not infrequently so perverted as to be actually harmful.

It is common to find that the difficult child is of neurotic heredity. The spoilt child is frequently the result of an inferiority complex on the part of the mother, or irresponsible indulgence on the part of one or other parent. Sometimes difficulty is due to excessive firmness in control, either on the part of parents or of school teachers. The error of the parents in such cases may be due to lack of sympathetic discernment, or at other times to misguided or excessive zeal for the welfare of their child. When the difficulty is the result of school control, its basis is often an unrecognized physical disability, frequently one of the special senses.

Excessive and misguided care by parents is part of a modern turn towards the psychological aspects of health and illness, and only too often serves as an illustration of what has been termed in the States the ' menace of psychiatry.' Thus we meet with mothers intensely aware of the power they wield in fashioning the health and happiness of their children through psychical influence. Such mothers, awed by this knowledge, may on the one hand flutter ineptly, and by their vacillation merely encourage the development of childish disorder; or on the other hand, obstinately resolute in carrying out their superficial psychiatric information, they may cause trouble through misguided effort.

We have experienced the power and also the danger of the results of the psychological states of doubt, indecision, and fear in relation to the diet and the digestion of young children, and particularly babies. A doubting, 
undecided, fearful mother gives her baby indigestion, whether it be breast- or bottle-fed. The lay parent, inflated with hearsay knowledge of all the vitamins, and all the superficial bio-chemistry of the food-stuffs, runs a danger of continuing the trouble. In like manner there is a danger to children in the unwise exercise of lay and domestic psychiatry. This danger is fostered by the widespread use of standard psycho-metric tests, the development of Child Guidance Clinics, the free discussion of the definition of mental defect and the limits of certification, and the increase of attention to feebleminded children. All such activities are unquestionably useful and desirable, but require to be kept in proper perspective, and our difficulty is in preventing the lay individual from applying tests, observations, supervision, etc., which while true and correct generally for the mass, are only of value in the case of the individual child when used with suitable discrimination, and when considered along with all other factors.

Remedial measures.-During the past 50 years, and largely owing to the passing of the several Education Acts, there has ensued a gradual tabulation of groups of children with an educational object in view, but largely on medical lines. Medicine and education have become more and more closely intertwined until to-day in our various Special Schools, Hospitals with Schools, and Residential Institutions of different kinds, the two are conjoined in one. With the division of children into massive groups, there has been separated as a special group those children who are described as ' maladjusted,' ' nervous,' ' difficult' ' unmanageable,' or ' neurotic,' and to deal with the problems their cases present Child Guidance Clinics have been instituted. Some of these children are a-social, some are unable to fit into their environment, and in many cases the environment is such as to prohibit normal development.

It is not only or indeed mainly Child Guidance which is called for, rather is it the guidance or manipulation of environmental conditions to fit the needs of the child.

To carry out the work, the clinic staff is based on the investigations of a social worker, a lay psychologist and a medical psychiatrist working in the closest union and in association with all authorities and services dealing with children. The mental and physical state of the child is determined, all available information regarding home, school, etc., is obtained, the cause or causes of difficulty are probed and decided upon, and a suitable form of remedy or remedies is formulated and efforts made to have it carried out. These children may be physically healthy or physically defective, and they may be mentally normal or mentally defective.

If they are physically defective, measures are taken to ensure proper treatment, and if they are mentally defective they are referred for certification and consequent suitable disposition.

A Child Guidance Clinic properly staffed does good work which otherwise will not be carried out. This type of Clinic is certain to develop; and though it is possible and, I think, right to regard it as only a temporary necessity, yet 
until medical and social conditions develop considerably, it is bound to fill a gap in prophylactic and therapeutic pædiatrics. Its work does not encroach on that of the general practitioner, and further the work is such as cannot at present be done by the general practitioner. Really good work at a clinic can only be carried out when the controlling head is a pædiatrist with psychiatric training, and pædiatrics in this country is still regarded as so subsidiary a subject in the undergraduate curriculum that only the experienced general practitioner can be, as so often he is, a valuable adviser in the subject. The work is most time-absorbing, and until society recognizes the need and is able and prepared to recompense doctors adequately for work performed, it is impossible for the individual to undertake it.

\section{Defective children.}

Just as ' difficult' is a vague term, so likewise is ' defective,' and no exact medical meaning is attached to the expression. We all constantly meet with defective children of many types, and in private practice, if we use the adjective at all, we may employ it loosely and as indefinitely as we please.

Classification.-But different types of defective children are defined by Acts of Parliament, the main Acts concerned with the subject being the Education Act, 1921, and the Mental Deficiency Acts, 1913-1927.

The definitions in these Acts were formulated for specific purposes, education, segregation, protection, etc., and in their construction and declared signification pass beyond pure medicine. It is therefore possible to attach different meanings to the terms, according as they are employed in the official sense or otherwise; or conversely, to have differing opinions on the proper designation of a particular child. In the formal use of these terms, however, it seems only wise and right to employ them in the official sense, and particularly is this the case when dealing with mental defect. Accurate diagnosis not infrequently discloses double defect, physical and mental.

In all cases both medical care and education are important factors in treatment, and it is imperative to decide whether the calls of medical care should be paramount with education as subsidiary (e.g., prevention of established rheumatic carditis, cure of tuberculous joint), or whether the outstanding factor in placement is educational and depending on mental capacity (e.g., birth trauma).

I have already spoken of the 'difficult' child, and the ' difficult' child may be and often is regarded as a bad child. No wise man can minimize the value of a good mental and moral heredity, or fail to recognize the success that usually accrues when this is conjoined with a good mental environment. On the other hand a child of poor heredity with correspondingly poor mental environment may be naturally inclined to be naughty or bad: we must, in a 
word, accept the existence of the bad child while emphasizing the causal importance of environment.

There is also, defined by statute, the child who is to be termed a ' moral defective,' i.e., the child ' in whose case there exists mental defectiveness coupled with strongly vicious or criminal propensities and who requires care, supervision and control for the protection of others.'

The primary essential, then, in concluding that the misdeeds of a child are such as to bring it within this classification, is that he should be considered mentally defective. If his badness is to be regarded as the evidence of mental defect it must be demonstrated that he does not and cannot recognize the difference between right and wrong, or else we must conclude that there exist general or other grounds for considering him mentally defective and that his badness is part of general mental lack.

Feeble-minded children of both sexes are often easily led into evil ways, but a true moral defective is uncommon in childhood. During the six years, 1925 to 1930 inclusive, there were certified as moral defectives seven children of school age in Liverpool, five of these being post-encephalitics. Fifteen other children certified as feeble-minded were excluded from school because of conduct detrimental to other children.

So far as the special senses are concerned, the interpretation of the terms 'blind' and ' deaf' in the Act (Ed. Act, 1921, p. 42) is as follows:-The expression 'blind' means too blind to be able to read the ordinary school books used by children: the expression' deaf' means too deaf to be taught in a class of hearing children in an elementary school.

Certification.-A child is certifiable as physically defective when 'by reason of physical defect he is incapable of receiving proper benefit from the instruction in the ordinary public elementary schools, but is not incapable by reason of that defect of receiving benefit from instruction in special classes or schools.' (Education Act, 1921, p. 35.)

Under this certification many surgical cases, mainly orthopædic, obtain medical supervision and education both in residential and day special schools. While there is much difference of opinion regarding the desirable placement of many cases after they have ceased to require residential care, the special practical training, and the special facilities for continuous surgical supervision in day special schools are important considerations. In these day special schools also many purely medical cases, such as of severe heart disease, derive benefit unobtainable in their cases in a public elementary school.

The subject of mental deficiency is more complicated than that of physical deficiency, the primary difficulty being in the precise interpretation of the definition. Many misconceptions exist regarding it both among the laity and members of our profession, and it is regrettable when the term is professionally employed in obvious ignorance of the signification attached to it. Of the classes of persons who are to be deemed mentally defective apart from moral defectives, those of the lowest grade are idiots, those of the next grade imbeciles, and the highest grade of all are feeble-minded. 
Idiots and imbeciles are from the purely medical aspect unmistakably mentally defective children, a good example of the latter being a mongol. Feeble-minded children sometimes are clearly defective, but very often accurate diagnosis demands intimate personal knowledge, as well as reports from various sources. Among the higher-grade feeble-minded, the borderline cases, a probation period for special observation is usually essential.

Feeble-minded children are defined in the Mental Deficiency Act as persons ' in whose cases there exists mental defectiveness which, though not amounting to imbecility, is yet so pronounced that they appear to be permanently incapable, by reason of such defectiveness, of receiving proper benefit from the instruction in ordinary schools.' This definition, on the face of it, appears purely scholastic, and this aspect is endorsed by the section in the Education Act, 1921, dealing with the subject, where feeble-minded children are considered those who by reason of mental defect are incapable of receiving proper benefit from the instruction in ordinary schools, but are not incapable of benefiting from instruction in special schools.

The response to scholastic environment and instruction is considered in both Acts a just criterion of social adaptability and potentiality; or, to express this from the practical point of view, school status and progress, regarded from a broad social aspect, is the most important test of a child's mental capacity.

It seems right that such a concept should form the basis of diagnosis, and if advisable certification; and in 1929 a Committee, appointed by Sir George Newman to consider the problems presented by the mentally defective child, reported that in its opinion mental defect should be regarded as a lack in capacity of social adaptation, either primary or secondary in origin.

Certification of mental defect is governed by the definition in the Mental Deficiency Act, 1913, as amended in 192\%. Here it is laid down " for the purposes of this section ' mental defectiveness' means a condition of arrested or incomplete development of mind existing before the age of eighteen years, whether arising from inherent causes or induced by disease or injury." This gives very wide latitude in diagnosis of the fundamental condition, particularly as the onset of mental defectiveness is noted as being possible at any time up to the age of eighteen years.

Many early cases of secondary amentia do not live till school age, and these cases of early death are mainly in the lower grades of mental defect. Some cases of mental defect are not obvious before school age, and these are usually of the higher grade and primary in nature. Thus at school age primary amentia is much more common than secondary amentia, and a great deal of it is of high-grade, that is, among the feeble-minded.

The fact that by statute mental defect is recognized as originating at any time up to the eighteenth year. of life, necessarily modifies this statement, but it remains true that the great majority of high-grade mental defectives of school age are cases of primary amentia. 
During the seven years 1925 to 1931 inclusive, there have been certified in Liverpool 2,128 children of school age as mentally defective-namely, 1,540 feeble-minded, 530 imbecile, 32 idiot, and 26 detrimental to other scholars.

About one-third or 30 per cent. of cases which are referred for examination as suspect are after a period of probation permanently retained in the ordinary school; no child is certified mentally defective until it appears conclusively proved that he comes definitely within the scope of the terms of the Act.

The fullest reports from head-teacher, school medical officer, and any agency interested in a particular case, are in the hands of the certifying officer-a full series of intelligence tests is made, personal examination carried out, and frequently a period of probation in an ordinary school is granted.

The numbers given are out of a school population of approximately

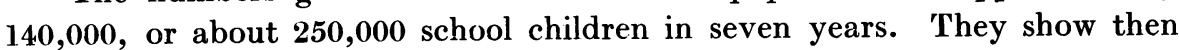
that while about one in 85 school children have been reported as suspect of mental defect to the certifying officer, about one in 130 have been certified as mentally defective; and that about one in 10,000 school children have been certified and excluded school because of their behaviour.

In the Special Day Schools for feeble-minded children, the desirable intelligence quotient at entrance appears to be between 60 per cent. and 70 per cent. A good scholastic standard for the leaving child of 16 years is that equivalent to the normal child of 9 or 10 years, and most of these children are fully competent to deal with a humble job.

There are certain basal problems still undecided. Thus it is generally recognized that for mentally and scholastically retarded children, special educational attention is necessary; but there is no unanimity of opinion as to either the wisest definition and separation of groups within the limit of retarded children, or where the special attention necessary for different groups should be obtained.

The basal medical problem is sometimes insoluble:-is this borderline child rciarded mentally and scholastically because of inherent mental defect, or because of lack of opportunity, of proper care, of illnesses or injury?

The position is greatly simplified by statute which calls for no exact differentiation in ætiology; but such broad generalization in classification certainly justifies the question whether or no the term mental defective is wise or right for higher-grade borderline cases in childhood.

In considering the figures given above for the years mentioned it has to be borne in mind that for the previous years-particularly the immediately preceding nine years of school life-ascertainment was inevitably less systematic and thorough, and consequently there is certainly included in them an unknown number of certified children carried over from a previous time. The term 'mentally defective' still carries with it a stigma, and 
is one which may automatically cease to be applicable to the individual on reaching the age of 16 years. At this age certification in terms applicable to childhood ceases, and unless further steps are taken the mentally defective child does not proceed to become a mentally defective adult.

Of 1,200 children certified as feeble-minded in the last six years, 170 automatically became decertified on reaching the age of 16 years (roughly 15 per cent.), while 93 were decertified before that age (roughly 8 per cent.), i.e., in all about 23 per cent. of those children certified as 'feeble-minded' were not certifiable at the age of 16 .

I would quote a recommendation from the Report of the Mental Deficiency Committee of the Board of Education and Board of Control, 1929 (p. 157), in which it is stated: 'We recommend the abolition of the requirement that the Local Education Authority should certify a particular type of child as mentally defective as a necessary preliminary to providing him with the type of education he requires.' 